\title{
Study on University Finance Funding Construction Project Risk Expense Control
}

\author{
Feng Wei \\ Beijing Institute of Economic and Management \\ Beijing, 102602 China
}

\begin{abstract}
The goal of conducting risk expense evaluation is to solve the deviation problem of actual investment and planning investment in university finance funding construction project. But a large number of examples prove that, in order to effectively control risk cost, we must combine prevention and control, namely, reasonable evaluation project, based on risk cost, we should fabricate effective risk monitoring measures to prevent risk influence factors, so that it can ensure the university finance funding construction project investment grasp in limited amount, in order to achieve the evaluation, namely, saving financial savings.
\end{abstract}

Keywords: financial funding; construction project; risk expense; control;

\section{I.INTRODUCTION}

With the social development and progress, construction project of financial funding has a large scale and a certain social publicity to be focused by society. In " $12^{\text {th }}$ five year" plan, every year the nation has to input hundreds of billions of funds for the construction of education, science, culture and other infrastructure facilities. But for the completion of funding construction of the project, it is not difficult to find that it often has finance amount, which can not complete the project declaration phenomena content. Investigating its reasons is because construction unit conducts project pre-estimation, the whole evaluation is not accurate, and the evaluation cost is without reasonable and accurate evaluation risk cost, it is the source of overall evaluation inaccuracy.

The goal of conducting risk expense evaluation is to solve the deviation problem of actual investment and planning investment in university finance funding construction project. But a large number of examples prove that, in order to effectively control risk cost, we must combine prevention and control, namely, reasonable evaluation project, based on risk cost, we should fabricate effective risk monitoring measures to prevent risk influence factors, so that it can ensure the university finance funding construction project investment grasp in limited amount, in order to achieve the evaluation, namely, saving financial savings.

\author{
Li Dianzuo \\ Beijing Institute of Economic and Management \\ Beijing, 102602 China
}

\section{II.THE CONNOTATION OF RISK COST CONTROL}

The risk cost control is actually eliminating the influence factor of risk event, in order to control the possibilities of risk factors.

Risk control is to further adopt control measures to reduce risks after risk recognition and risk evaluation, in order to avoid events.

First, university finance funding construction project risk cost control is based on risk factor control, although risk factor is hard to avoid, yet most risk factors are mostly preventable. Secondly, university finance funding construction project risk expense control is the proposed control measures through scientific risk analysis, which has some scientifics.

\section{III.EXISTING PROBLEMS OF UNIVERSITY FINANCE FUNDING CONSTRUCTION PROJECT RISK COST COMPOSITION}

Based on the features of university finance funding construction project, and combined with the research results, we can find that the current risk fee composition has the following problems, for university finance funding construction project.

(1)Compared with other types of projects, university finance funding construction project has different risk factors. If we adopt the same composition and evaluation method with other types of projects, it is obviously hard to guarantee the smooth implementation of university finance funding construction project.

(2)In project implementation process, university finance funding construction project architecture installation engineering stage, the influence is the largest, because the project participation staff are numerous, the input finance and materials are numerous, corresponding unpredictable factors are many.

It originates from that university finance funding construction project is national finance funding, and the phenomenon reflects more prominent. So, it is mainly reflected that because a lot of unpredictable risk factors cause the fee increase, numerous risk factors will further develop and evolve, new identified risk factors will constantly emerge.

(3)Currently, the national price adjustment is normally according to supply and demand requirement, for unified time adjustment. For the project within one year of construction period, if the construction period is in price adjustment period without accounting price increase in 
risk fee, it will appear price rise but the project overall investment keeps unchanged, it will make the project hard to implement.

\section{IV.EXISTING PROBLEMS OF UNIVERSITY FINANCE FUNDING CONSTRUCTION PROJECT RISK COST \\ MANAGEMENT}

The usage and management of project pricing in China obtain good performance and achievement, it provides great support and help for our national project construction field. But it still has many problems, with specific reflection in the following aspects:

(1)University finance funding construction project risk cost is generally distributed by university basic construction management department. The university construction management department is very blind and random in risk cost usage, control and management, and most university construction management department lacks of management experience, without according to project features to fabricate corresponding countermeasures. Many university capital construction management department leaders will arrange the use of part of the funds according to their own willingness. What's more, part of university construction management departments have not been aware of risk cost, thinking construction project pricing is determined by certain cost, not to mention risk monitoring countermeasures.

(2)The project fee control is understood as project fee planning value and actual value comparison, when the project actual price is deviated from target value, we can analyze the reasons and determine the make-up countermeasures.

This

finding-control---correction---finding again---correction again method can only find deviation, but it can not truly make the unproduced deviation have reducing rate or reducing.

(3)Currently, university focuses work on capital approval, and when the money is got, what to do is next. In project approval estimation stage, without according to project feature to consider specific project risk factor, it can conduct reasonable evaluation project risk fee, thus, it leads to most university finance funding construction project to have "three super" phenomenon, namely, final account exceeds budget, budget exceeds super budget, super budget exceeds estimates, so that some projects are out of control, causing huge losses.

(4)Professional risk theory lacks and university construction management department and technical personnels lack of economic conception, simply thinking the project pricing is not related with project economic benefit, which is related with pricing staff. Corresponding pricing staff don't pay attention to construction process, lacking of effective first materials, and university construction management department lacks of project field management experience, technical staff and economic staff are not related, and the result is tht project pricing evaluation is not accurate and cannot control.

\section{V.COUNTERMEASURES OF UNIVERSITY FINANCE FUNDING}

\section{CONSTRUCTION PROJECT RISK FACTOR CONTROL}

For university finance funding construction project, in order to obtain expected results, it should fabricate corresponding risk factor control countermeasures, and we should control from two aspects. One is to control the previous mentioned risk evaluation ranking focus risk factor fabricated professional measure control. Two is to strengthen the quality education of relevant staff, in order to ensure the effective implementation of control measures.

\section{(1) Focus Risk Factor Specific Control Measure of Risk Evaluation}

1) Control Measures of University Construction Management Department and Design, Supervision Unit Coordination and Communication Inefficiency.

In implementation process of project, we should strengthen university construction department and design, monitoring unit for timely communication and have clear relationship with each other.

\section{2)Design Exceeding the Standard (Without Limited Design)}

Conducting review of the designed document and further strengthening can avoid the design exceeding the standard. Strengthening the review of designed documents, for the design exceeding standard risk factor causing risk fee loss can have effective restrictive role. Thus, we can see that strengthening designed document review is very important. Through research, we can obtain, the review work of strengthening designed document can be conducted from the several aspects: we should carefully review the design document and entrust the corresponding qualified third party to complete the audit work of the original design, to flexibly use various kinds of economic technical index control design.

\section{3)For Unreasonable Control Measures of Contract from Signing}

Strengthening contract management and adopting reasonable and suitable university construction project feature, it plays an important role of whole implementation link of project. In order to avoid the loss of contract risk fee, as the university construction management department, we should accumulate the daily project materials, project contact list and other relevant documents. In the construction stage, various contract disputes and claims often occur, it is because of unreasonable contract form, relevant parties responsibility division is not clear on the terms of contract and their difference in understanding the cause, so fully and effectively strengthening the contract management, the reasonable form of contract, we should better achieve effective risk control of project cost.

4)For Unreasonable Project Management Organization Structure, unclear control Measures of Responsibility Definition

The project management department of owners, namely, university construction management department 
should choose rich practice experience, strong work ability, upright and responsible for management of engineering construction projects. At the same time, the project participants should straighten out the relationship, further implementing relevant management systems for definition and division of responsibility. It is necessary to fabricate reasonable effective reward and punishment, which plays a certain encouragement and incentives, such as ensuring the quality of projects to be realized and budget control in the target range, to give some material reward and spiritual praise.

\section{5) Control Measures of Adopting New Technology to Cause Construction Difficulty}

We should do the following points: first we should choose upright, rich work experience, professional practical ability strong management staff's responsible management staff project construction work. Secondly, we should fabricate and implement various rules for the project features, have clear about the relevant relationship with relevant participants, to have clear unity of responsibility and rights. Finally, we should establish the incentive mechanism, fabricate relevant reward and punishment policy, in order to give a certain reward and recognition of behavior and staff in realizing project construction quality, budget in control target.

\section{(2) To strengthen the quality of education-related personnel}

To prevent and reduce losses due to their own reasons which led to the construction unit cost of risk should be a corresponding increase in the quality of university infrastructure management department managers. In practical engineering, such as university infrastructure management project management organization structure is irrational, lengthy internal management structure, lack of project management experience, ill-defined responsibilities and rights, such as poor information transfer occurs frequently. Now in college financial allocation in construction projects, the pursuit of individual leaders and managers ostentation, corruption, abuse of power greatly phenomenon exists, but management professional level is not high, the lack of engineering experience. Therefore, in order to solve the above problems, we should do the following: First, should choose upright style, work experience, building strong professional practice managers responsible for the project; secondly to formulate rules and regulations for the implementation of the characteristics of the project, rationalize the relationship between the parties involved in project-related, clear responsibilities and rights of unity; finally, establish incentives, reward and punishment formulate relevant policies to ensure the realization of the project construction quality, the proposed budget and personnel in the control behavior of the target to give some reward and recognition. In addition, the need for university infrastructure management personnel regularly organize training to meet the needs of the industry.

\section{VI.CONCLUSION}

In a word, for relevant project example investigation, we can find that, through fabricating reasonable and effective university construction project's relevant control measures of its own features, it can greatly reduce or prevent risk event, which can greatly ensure the overall capital control in limited range, and it conforms to our research target.

\section{References}

[1] Chen Huazhi, Xiao Xuexiang. Analysis on project owners for engineering pricing control in project implementation process Scientific situation development and economy. 2011. P18. TU723.3.

[2] Lu Wei. National P.E stadium project risk evaluation practice. Project construction independent innovation and scientific development.

[3] Wen Guofeng. Construction project investment evaluation model Chinese Coal Economic College Journal[J]. 2008,3.

[4] Beijing finance funding construction project management rules. Beijing project [2009]31.

[5] Yang Ping. Analysis on higher college engineering pricing control[J]. Project and Construction. 2009,4. 